\title{
Hepatitis B Vaccine Nonresponse: An Alarm Signal for Latent Type 1 Diabetes?
}

\section{Raffaella Mormile* and Giovanna Pannullo}

Division of Pediatrics and Neonatology, Moscati Hospital, Aversa, Italy

Hepatitis B virus (HBV) infection affects more than one third of the world's population causing acute and chronic liver diseases, ranging from fulminant hepatitis to cirrhosis and eventually hepatocellular carcinoma with an incidence of 620.000 death per year $[1,2]$. Vaccination with the surface antigen of $\mathrm{HBV}(\mathrm{HbsAg})$ is considered as the main safe and effective strategy for protecting people from common $\mathrm{HBV}$ infection $[1,2]$. HB vaccination is routinely recommended for infants, children, and adolescents [1,2]. Moreover, it has also been suggested for high risk adults for acquiring HBV infection. Development of immune response to $\mathrm{HbsAg}$ is connected with the production of specific neutralizing antibodies to surface antigen of HBV (anti-HBs) [3]. Current recombinant $\mathrm{HBV}$ vaccines show excellent immunogenicity [3]. However, approximately 5-10\% of immunized individuals are enabled to develop the minimum protective anti-Hbs titers of $10 \mathrm{mIU} /$ $\mathrm{ml}$ after completion of primary vaccine series remaining at risk for $\mathrm{HB}$ infection [3]. The group of non responders patients could represent an important reservoir of HBV susceptible persons that will persist as healthy carriers, contributing significantly to the spread of the disease $[1,2]$. It has been estimated that there are more than 350.000 million of chronic HBV carriers in the world [3]. Thus, the problem of unresponsiveness to HBV vaccine constitutes a critical public health matter worldwide [1]. In this respect, alternative $\mathrm{HBV}$ vaccination schedules have been proposed to improve the responsiveness to $\mathrm{HB}$ vaccine in this patient category $[1,2]$. To date, the underlying mechanisms responsible for non response phenomenon against $\mathrm{HbsAg}$ in vaccinated healthy subjects are poorly understood [2-5]. The process of ant-HBs production is T cell-dependent and requires T helper (Th)cell activation [3]. In particular, T cell type 1(Th1) immune response has been considered as a prerequisite of HBV clearance [4]. Consequently, altered Th1 immune response has been thought to account for non responsiveness to the HBV vaccine [3-5]. Anti-HBs production has been correlated with gene polymorphisms of interleukins involved in the Th1 system such as IL-18 and IFN- $\gamma$ [4-9]. On this regard, it is well recognized that IL-18 strongly enhances the secretion of interferon- $\gamma$ (IFN- $\gamma$ ) which, in turn, further skews the immune response toward a Thl phenotype [7]. The outcome of HBV infection has been associated with IL-18 gene polymorphisms [4]. IL18 has been reported to regulate HBV clearance and the immune response to $\mathrm{HBV}$ antigens during spontaneous natural infection or planned vaccination $[6,8]$. Interestingly, it has been demonstrated that $\mathrm{HB}$ core antigen is a potent inductor of IL-18 from healthy controls and patients with chronic HB or acute HB [6]. Regarding IFN- $\gamma$, it has been verified that genetically determined differences in IFN- $\gamma$ activity could impact on the magnitude of immune response to HBV vaccination [10]. Furthermore, IFN- $\gamma$ gene polymorphism has been correlated with susceptibility to chronic HBV infection and development of intrauterine $\mathrm{HBV}$ infection $[10,11]$. Inter-individual variability in antibody response to $H B$ vaccination has also been linked to HLA genotypes [12]. It has been advised a possible genetic predisposition to elicit protective immunity against HBV likely due to the presence of specific human leukocyte antigen (HLA) haplotypes $[1,12,13]$. On this regard, HLADRB1 gene has been directly involved in HBV vaccine non responsiveness [12]. Intriguingly, HLA-DRB1 alleles have been described as major predictors of differential antibodies responses to HBV vaccination in youth, implying that Th cell-dependent pathways mediated through HLA Class II antigen presentation are essential to effective immune response to recombinant vaccines [13]. It has been reported a lower response to HBV vaccination in chronic conditions such as Type 1 and Type 2 diabetes than in healthy controls $[1,2,14,15]$. Type 1 diabetes is a chronic autoimmune disorder related to genetic, environmental and immunologic factors that ultimately leads to the destruction of the pancreatic $\beta$ cells and insulin deficiency [16-19]. It is the most common pediatric endocrine disease that is fatal unless treated with insulin $[16,18]$. It has been estimated that approximately 65,000 children aged under 15 years are diagnosed worldwide every year [20].Up to $80 \%$ of these patients present with diabetic ketoacidosis (DKA) that is linked to both short-term risks and long-term consequences [20]. It has been underlined that children with Type 1 diabetes show a higher rate of reduced seroprotection for HBV vaccination [1]. Previous studies found a reduced efficacy of HBV vaccination both in chronic diabetic adults and in children [1,14,15,21]. Recently, it has been written that older adults suffering from diabetes and obesity seem to have a greater impairment in HBV vaccine response, principally those affected by coexisting kidney diseases in comparison to the same group of high risk patients without diabetes $[1,14]$. In this contest, the Advisory Committee on Immunization Practices (ACIP) recommended use of HB vaccination for adults with diabetes mellitus because of the increasing incidence of diabetes, and the high prevalence of diabetes among certain groups recommended for $\mathrm{HB}$ vaccination as patients with end-stage renal disease [22]. The biological basis for impaired responses to HBV vaccination among individuals with diabetes still remains unclear [14]. The lowseroconversion rate in diabetic patients represents a critical problem considering that they have a number of risk factor for enhancing HBV exposure including self-monitoring of blood glucose, intravenous and subcutaneous insulin administrations [1,2]. Similarly to unresponsiveness to HBV vaccine, HLA DRB1genotypes have been illustrated as significant predictors for latent Type 1 diabetes [23]. It has been written that HLA profile may designate the link between Type 1 diabetes and non responsiveness to $\mathrm{HB}$ vaccine $[1,23]$. What is more, it has also been advised a central role for Th1response pattern in Type 1 diabetes development $[15,16]$. The inflammatory process in early diabetes is thought to be started and propagated by the effect of Th1-

*Corresponding author: Raffaella Mormile, Division of Pediatrics and Neonatology, Moscati Hospital, Via A. Gramsci, 3 - 81031 Aversa, Italy, Tel: +390815001503/+393392045468; E-mail: raffaellamormile@alice.it

Received July 15, 2013; Accepted August 17, 2013; Published August 22, 2013

Citation: Mormile R, Pannullo G (2013) Hepatitis B Vaccine Nonresponse: An Alarm Signal for Latent Type 1 Diabetes? J Diabetes Metab 4: 282. doi:10.4172/21556156.1000282

Copyright: (c) 2013 Mormile R, et al. This is an open-access article distributed under the terms of the Creative Commons Attribution License, which permits unrestricted use, distribution, and reproduction in any medium, provided the original author and source are credited. 
secreted cytokines [16]. Intriguingly, IL-18 and IFN- $\gamma$ among other Th1 cytokines, have been shown to play a major role in $\beta$-cell dysfunction $[14,17,24-26]$. It has been detected that serum levels of the IFN- $\gamma$ inducing IL-18 are increased in individuals at high risk of developing Type 1 diabetes [18]. IL-18 gene promoter polymorphism has been linked to susceptibility to Type 1 diabetes [24]. IL-18 has been described as an enhancer of Th-1-type immune responses in diabetes development early in the spontaneous disease process [25]. IFN- $\gamma$ gene polymorphism has also been found to be strongly linked to Type 1 diabetes onset [14]. IFN- $\gamma$ seems to be crucially involved in $\beta$-cell dysfunction related to chronic pancreatitis in diabetic and non diabetic patients in comparison to controls [26]. Interestingly, it has been shown that IL-18 and IFN- $\gamma$ also play a critical role in susceptibility to obesity and Type 2 diabetes $[27,28]$. The prodromal phase of Type 1 diabetes is characterized by the appearance of multiple islet-cell related autoantibodies (Aab) [29]. There is general consensus that the presence of multiple Aab is associated with a high risk of developing diabetes, where the presence of a single isle-cell -related Aab has usually a low predictive value [27]. Until today no treatment has been shown to prevent Type 1 diabetes in humans [18]. All these contentions led us to presume that HBV vaccine non response and Type 1 diabetes may share common immunological mechanisms in physiopathology. We hypothesize the potential pathogenic role of IL-18 and IFN- $\gamma$ gene polymorphisms in HBV vaccination failure with the possibility of long-lasting downstream effects on the pancreatic $\beta$ cells leading to their gradual destruction and insulin deficiency. Thus, nonresponsiveness to the HBV vaccine may be an alarm signal for latent Type 1 diabetes. For that reason, postvaccination testing for serologic response should be performed after primary series completion in children. Non- responder babies to HBV vaccination, especially those with familiarity for autoimmune disorders, should be screened for multiple islet-cell related Aab along the time. More likely, greater gains will occur with an approach that looks for identifying IL-18 and IFN- $\gamma$ gene polymorphisms to utilize as biomarkers for latent Type 1 diabetes. In this contest, administration of neutralizing antibodies against IFN- $\gamma$ and/or IL-18 might represent a future target for immunomodulatory intervention therapy to halt or even prevent islet- cell destruction. Moreover, by recognizing and treating the early symptoms of hyperglycemia, DKA can be prevented. As a final point, new vaccination strategies are needed to enhance HBV vaccine efficacy in these subjects at risk given that there is increasing incidence of Type 1 diabetes in the world, mainly among children younger than 5 years of age [30].

\section{References}

1. Leonardi S, Vitaliti G, Garozzo MT, Miraglia del Giudice M, Marseglia G, et al (2012) Hepatitis B vaccination failure in children with diabetes mellitus? The debate continues. Hum Vaccin Immunother 8: 448-452.

2. Vitaliti G, Praticò AD, Cimino C, Di Dio G, Lionetti E, et al. (2013) Hepatitis $\mathrm{B}$ vaccine in celiac disease: yesterday, today and tomorrow. World $\mathrm{J}$ Gastroenterol 19: 838-845.

3. Goncalves L, Albarran B, Salmen S, Borges L, Fields H, et al. (2004) The nonresponse to hepatitis $B$ vaccination is associated with impaired lymphocyte activation. Virology 326: 20-28.

4. Grzegorzewska AE, Wobszal PM, Mostowska A, Jagodzinski PP (2012) Antibodies to hepatitis B virus surface antigen and interleukin 12 and interleukin 18 gene polymorphisms in hemodialysis patients. BMC Nephrol 13: 75.

5. Ma K, Xu W, Shao X, Yanyue, Hu L, et al. (2007) Coimmunization with RANTES plasmid polarized Th1 immune response against hepatitis $B$ virus envelope via recruitment of dendritic cells. Antiviral Res 76: 140-149.

6. Manigold T, Böcker U, Chen J, Gundt J, Traber P, et al. (2003) Hepatitis B core antigen is a potent inductor of interleukin-18 in peripheral blood mononuclear cells of healthy controls and patients with hepatitis B infection. J Med Virol 71 $31-40$
7. Schroder K, Hertzog PJ, Ravasi T, Hume DA (2004) Interferon-gamma: an overview of signals, mechanisms and functions. J Leukoc Biol 75: 163-189.

8. Cheong JY, Cho SW, Oh B, Kimm K, Lee KM, et al. (2010) Association of interleukin-18 gene polymorphisms with hepatitis B virus clearance. Dig Dis Sci 55: 1113-1119.

9. Hennig BJ, Fielding K, Broxholme J, Diatta M, Mendy M, et al. (2008) Host genetic factors and vaccine-induced immunity to hepatitis $B$ virus infection PLoS One 3: e1898.

10. Khanizadeh S, Ravanshad M, Mohebbi SR, Naghoosi H, Abrahim Tahaei M, et al. (2012) Polymorphisms within the Promoter Region of the Gamma Interferon (IFN- y) Receptor1 Gene are Associated with the Susceptibility to Chronic HBV Infection in an Iranian Population. Hepat Mon 12: e7283.

11. Yu H, Zhu QR, Gu SQ, Fei LE (2006) Relationship between IFN-gamma gene polymorphism and susceptibility to intrauterine HBV infection. World $J$ Gastroenterol 12: 2928-2931.

12. Li Y, Ni R, Song W, Shao W, Shrestha S, et al. (2009) Clear and independent associations of several HLA-DRB1 alleles with differential antibody responses to hepatitis B vaccination in youth. Hum Genet 126: 685-696.

13. Godkin A, Davenport M, Hill AV (2005) Molecular analysis of HLA class I associations with hepatitis $B$ virus clearance and vaccine nonresponsiveness. Hepatology 41: 1383-1390.

14. Schillie SF, Spradling PR, Murphy TV (2012) Immune response of hepatitis vaccine among persons with diabetes: a systematic review of the literature. Diabetes Care 35: 2690-2697.

15. Arslanoglu I, Cetin B, Isguven $P$, Karavus $M$ (2002) Anti-HBs response to standard hepatitis $B$ vaccination in children and adolescents with diabetes mellitus. J Pediatr Endocrinol Metab 15: 389-395.

16. Hassan GA, Sliem HA, Ellethy AT, Salama Mel-S (2012) Role of immune system modulation in prevention of type 1 diabetes mellitus. Indian J Endocrino Metab 16: 904-909.

17. Rafinejad A, Nikman MH, Amirzagar AA, Khosravi F et al. (2004) Association of IFN-y gene polymorphism with type I diabetes in Iranian patients. IJI 1: 130132

18. Barcala Tabarrozzi AE, Castro CN, Dewey RA, Sogayar MC, Labriola L, et al. (2013) Cell-based interventions to halt autoimmunity in type 1 diabetes mellitus. Clin Exp Immunol 171: 135-146.

19. Nicoletti F, Conget I, Di Marco R, Speciale AM, Morìnigo R, et al. (2001) Serum levels of the interferon-gamma-inducing cytokine interleukin-18 are increased in individuals at high risk of developing type I diabetes. Diabetologia 44: 309 311

20. Usher-Smith JA, Thompson M, Ercole A, Walter FM (2012) Variation between countries in the frequency of diabetic ketoacidosis at first presentation of type 1 diabetes in children: a systematic review. Diabetologia 55: 2878-2894.

21. Bouter KP, Diepersloot RJ, Wismans PJ, Gmelig Meyling FH, Hoekstra JB, et al. (1992) Humoral immune response to a yeast-derived hepatitis $B$ vaccine in patients with type 1 diabetes mellitus. Diabet Med 9: 66-69.

22. Centers for Disease Control and Prevention (CDC) (2011) Use of hepatitis vaccination for adults with diabetes mellitus: recommendations of the Advisory Committee on Immunization Practices (ACIP). MMWR Morb Mortal Wkly Rep 60: $1709-1711$.

23. Dong GP, Yu ZS, Liang L, Zou CC, Fu JF et al. (2007) IL-18 gene promoter $-137 \mathrm{C} / \mathrm{G}$ and $-607 \mathrm{C} / \mathrm{A}$ polymorphisms in Chinese Han children with type 1 diabetes mellitus. Int J Immunogenet 34: 75-79.

24. Oikawa Y, Shimada A, Kasuga A, Morimoto J, Osaki T, et al. (2003) Systemic administration of IL-18 promotes diabetes development in young nonobese diabetic mice. J Immunol 171: 5865-5875

25. Pavan Kumar P, Radhika G, Rao GV, Pradeep R, Subramanyam C, et al (2012) Interferon y and glycemic status in diabetes associated with chronic pancreatitis. Pancreatology 12: 65-70

26. Maioli M, Pes GM, Delitala G, Puddu L, Falorni A, et al. (2010) Number of autoantibodies and HLA genotype, more than high titers of glutamic acid decarboxylase autoantibodies, predict insulin dependence in latent autoimmune diabetes of adults. Eur J Endocrinol 163: 541-549. 
Citation: Mormile R, Pannullo G (2013) Hepatitis B Vaccine Nonresponse: An Alarm Signal for Latent Type 1 Diabetes? J Diabetes Metab 4: 282. doi:10.4172/2155-6156.1000282

Page 3 of 3

27. Zilverschoon GR, Tack CJ, Joosten LA, Kullberg BJ, van der Meer JW, et al. (2008) Interleukin-18 resistance in patients with obesity and type 2 diabetes mellitus. Int J Obes (Lond) 32: 1407-1414.

28. Rocha VZ, Folco EJ, Sukhova G, Shimizu K, Gotsman I, et al. (2008) Interferongamma, a Th1 cytokine, regulates fat inflammation: a role for adaptive immunity in obesity. Circ Res 103: 467-476.
29. Franke B, Galloway TS, Wilkin TJ (2005) Developments in the prediction of type 1 diabetes mellitus, with special reference to insulin autoantibodies. Diabetes Metab Res Rev 21: 395-415.

30. Frederiksen B, Kroehl M, Lamb MM, Seifert J, Barriga K, et al. (2013) Infant Exposures and Development of Type 1 Diabetes Mellitus: The Diabetes Autoimmunity Study in the Young (DAISY). JAMA Pediatr. 